\title{
IS VIETNAM'S EXCHANGE RATE OVERVALUED?
}

\author{
Duy Hung Bui \\ State Bank of Vietnam \\ Hanoi \\ Vietnam \\ Anthony J Makin* \\ Economics, Griffith Business School and Griffith Asia Institute \\ Griffith University
}

Australia 4222

Shyama Ratnasiri

Economics, Griffith Business School

Griffith University

Australia 4222

October 2016

* Corresponding author 


\title{
IS VIETNAM'S EXCHANGE RATE OVERVALUED?
}

\begin{abstract}
This paper focuses on Vietnam's exchange rate whose official rate has been pegged by the State Bank against the U.S dollar since 1989 despite wider market liberalisation over this time. Whether Vietnam's official exchange rate is appropriately valued has important implications for the economy's international competitiveness, trade balance and GDP. The main aim of the paper is to assess whether the official exchange rate has been valued appropriately with reference to macroeconomic fundamentals, as proposed by the Purchasing Power Parity (PPP) and the Behavioural Equilibrium Exchange Rate (BEER) approaches to evaluating equilibrium exchange rates. Our main empirical finding based on co-integration analysis using quarterly data from 1995 to 2014 is that according to both these approaches the Vietnamese Dong was significantly overvalued for extended times, most notably due to Vietnam's relatively high inflation rate.
\end{abstract}

Keywords: Vietnam, exchange rate, overvalued

JEL: F31 O24 


\section{IS VIETNAM'S EXCHANGE RATE OVERVALUED?}

\section{Introduction}

The transition of the Vietnamese economy from a centrally planned to market-oriented model in the mid-1980s led to major economic policy changes, including to exchange rate management. Identifying and estimating equilibrium exchange rates is critically important for highly open emerging economies like Vietnam since the exchange rate is central to influencing international competitiveness, trade balances and GDP. Yet what the best method of gauging the equilibrium value of an economy's exchange rate is at any point in time remains a controversial topic in international finance.

There is a paucity of academic research on the determination of Vietnam's exchange rate, although a few studies have addressed related aspects. For instance, Vo, Dinh, Do, Hoang, and Phan (2000) and Thanh and Kalirajan (2005) have examined the relationship between Vietnam's exchange rate movements and its foreign trade, finding that devaluations have a positive and significant impact. Meanwhile Vuong (2003) found evidence to support relative PPP for the Vietnamese dong in the long-run.

According to the International Monetary Fund (IMF 2013) the State Bank of Vietnam (SBV) has adopted a de facto fixed exchange rate by pegging its currency against the U.S dollar which it has done since 1989. The SBV adjusts the official exchange rate periodically according to macroeconomic conditions influencing the demand and supply of foreign exchange by officially announcing its value and the trading band in which it can fluctuate. Since 1999, this official rate has been based on the average of trading exchange rate on the interbank foreign exchange market.

The SBV has gradually devalued the exchange rate against the US dollar as shown in Figure 1, with notable devaluations occurring during the Asian financial crisis of 200809 and the transatlantic banking crisis of 2008-10. Over this time the official exchange rate tracked the parallel market rate reasonably closely although during these crisis episodes the market rate exhibited significantly greater weakness against the US dollar, Singapore dollar, Korean won, Malaysian ringgit, and Chinese renminbi (Vu, Nguyen, \& Vu, 2013). 
Figure 1 The Dong/US Dollar Exchange Rate 1995-2014

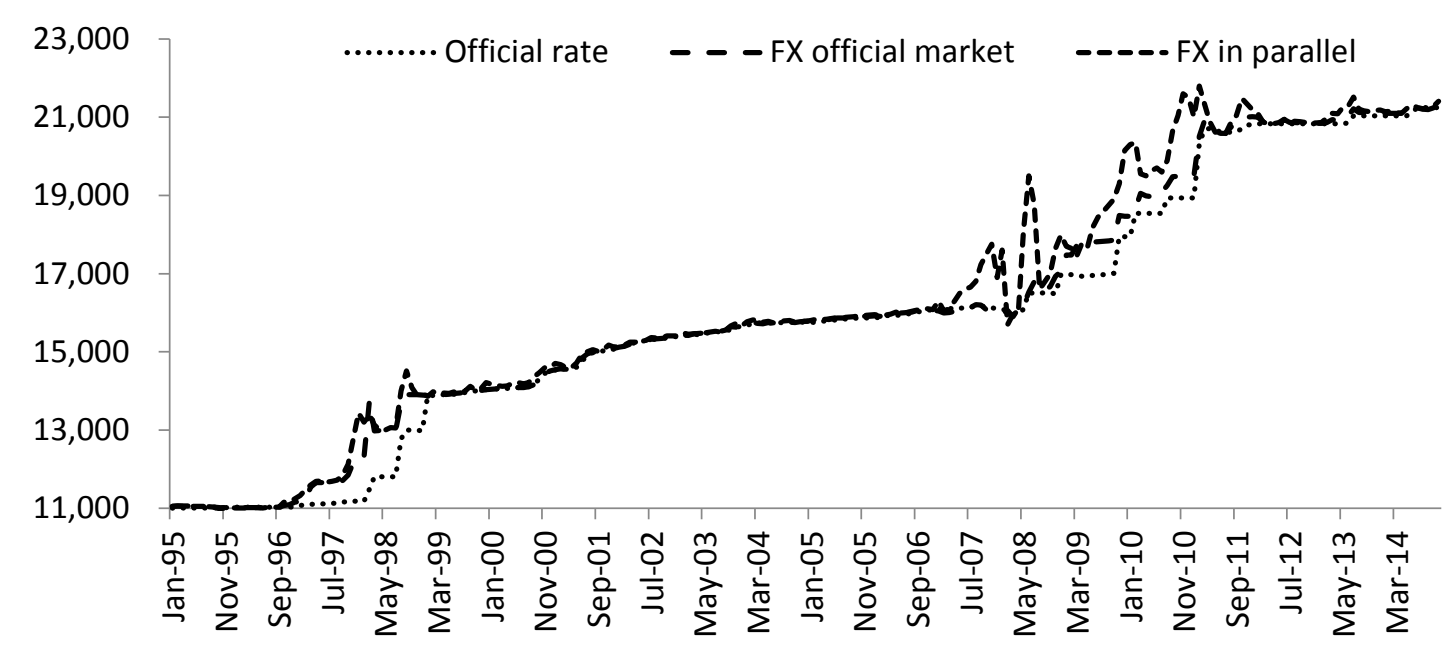

Source: the SBV and Reuters (various years)

Although, the SBV has gradually devalued the Vietnamese Dong (VND) against the United States Dollar (USD), the VND has arguably been overvalued due to relatively higher inflation rate in Vietnam compared to that of the United States over a lengthy period. The extent of this overvaluation was accentuated during the two crisis intervals, as reflected in the exchange rate premium defined as the gap between the exchange rate in the official and the parallel exchange market. (Figure 2).

Figure 2 The Exchange Rate Premium

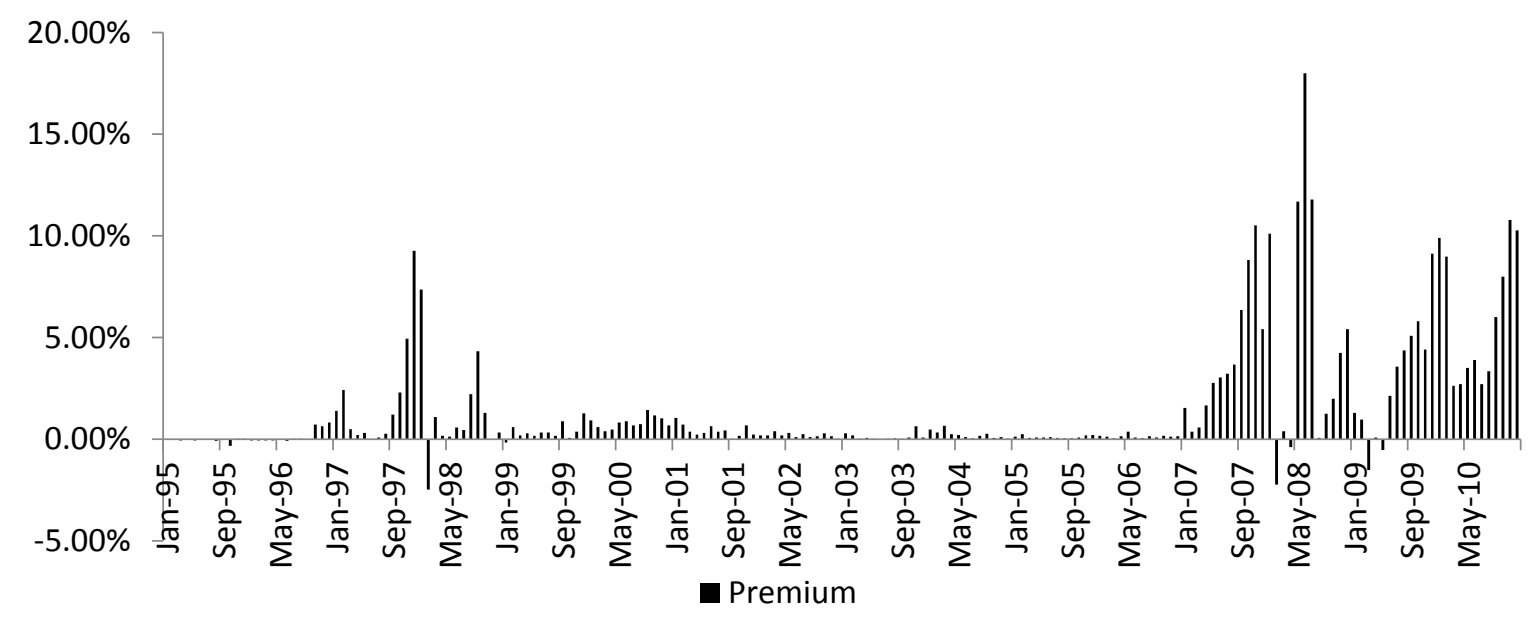

Source: the SBV and Reuters (various years) 
In the exchange rate literature, several techniques have been advanced to ascertain equilibrium exchange rate values. Once having established an equilibrium exchange rate, it then becomes possible to gauge the degree of under- or over-valuation of actual exchange rates at any point in time or through particular intervals. Approaches that have been developed for this purpose are the Purchasing Power Parity (PPP), Fundamental Equilibrium Exchange Rate (FEER), Behaviour Equilibrium Exchange Rate (BEER), and Natural Real Exchange Rate (NATREX) frameworks.

The FEER was introduced by Williamson (1994), wherein the equilibrium exchange rate is defined as the medium-term real effective exchange rate consistent with a macroeconomic equilibrium involving the current account of the balance of payments. However, as Clark and MacDonald (1999) point out, as an empirically based approach, the FEER method does not espouse a theory of exchange rate determination as such. NATREX analyses the determinants of the real exchange rate in the medium and long term. It is defined as the equilibrium exchange rate that would prevail, with the unemployment rate at its natural rate, and net of speculative and cyclical influences (Stein, 1993). Additionally, it extends the FEER approach using dynamic stock-flow models, with external balance explicitly modelled in terms of national savings and investment behavior (Berger \& Kempa, 2009).

Since the FEER and NATREX frameworks require data not readily available for Vietnam, we restrict our focus to the PPP and BEER modelling approaches in this paper, the remainder of which is organized as follows. In Section 2, theories of exchange rate equilibrium are briefly reviewed, while Section 3 outlines the data and methodology. Section 5 reports co-integration results from analysis of quarterly data from 1995Q4 to 2014Q2. The final section provides concluding summary remarks.

\section{Conceptual Foundations}

We first canvass the key concepts underlying the PPP and BEER approaches before testing them econometrically and reporting our main findings. 


\subsection{Purchasing power parity}

PPP has a long history in exchange rate theory. It is a theory that links the exchange rate between two countries to their price levels. Because of its simplicity, PPP is always the first reference for estimating an equilibrium exchange rate (Rogoff, 1996). This theory developed by Cassel (1918) is a means for setting relative gold parities in the context of setting exchange rates after World War I. Cassel proposed using price levels in both countries to calculate the exchange rate between the two countries. There are two version of PPP - absolute PPP and relative PPP.

Absolute PPP is defined as the exchange rate between two currencies which would equate the two relevant national price levels if expressed in a common currency at that rate, so that the purchasing power of a unit of one currency would be the same in both economies (Rogoff, 1996; Sarno \& Taylor, 2002). However, it is uncommon two different countries to have the same basket of goods and services for their respective CPIs (Taylor \& Taylor, 2004). Thus, relative PPP, the relationship between exchange rates and price levels in percentage change terms is often used instead. When absolute PPP holds, then relative PPP must also hold but the reverse does not always hold true.

PPP has a wide range of applications in exchange rate economics. It is often used as a model to choose the correct initial exchange rate and to determine whether a national currency is overvalued or undervalued, particularly for developing countries where there is considerable evidence that long-run PPP holds (Anoruo, Braha, \& Ahmad, 2002; Arize, 2011). Figure 3 illustrates how a national currency can be overvalued or undervalued with reference to the PPP approach (see also Makin 2017). It shows that the degree of under or overvaluation at any time can be gauged by comparing the actual value of the exchange rate at any given time with the value implied by the PPP relationship at that time. The vertical distance between these values indicates the extent to which the currency is misaligned. 
Figure 3 Currency undervaluation and overvaluation

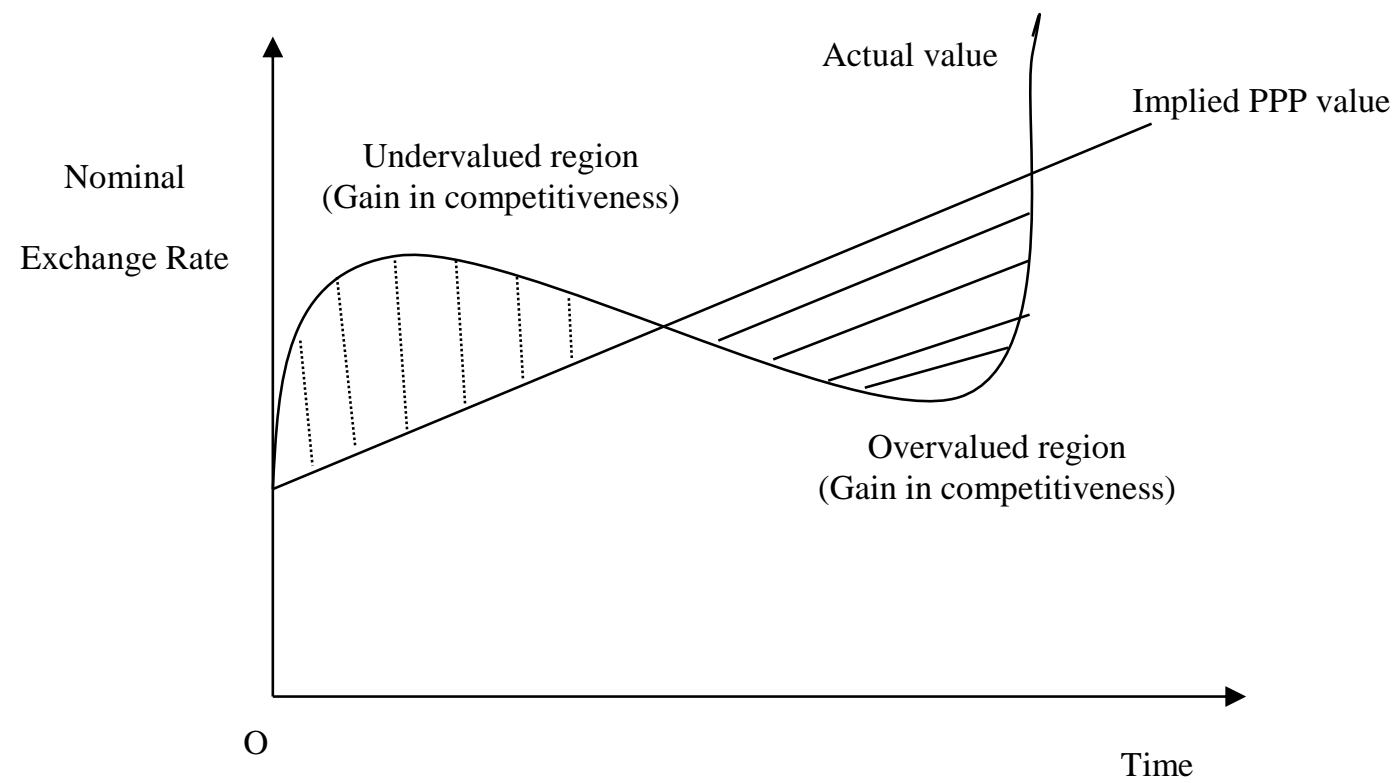

In countries with unofficial or black foreign exchange markets, testing black market rather than official rates has generally supported PPP (M. Bahmani-Oskooee \& Goswami, 2005; Mohsen Bahmani-Oskooee \& Tanku, 2006). Cerrato, Kellard, and Sarantis (2008) also found black market rates were superior to official rates as they better reflected underlying forces in foreign exchange markets, and hence, the true value of the domestic currency. PPP has been used in a number of Asian countries to test the equilibrium exchange rate with varied results. For instance, Thailand, Philippines and Malaysia exhibited overvaluation, while Korea and Indonesia were apparently undervalued in the period 1990-1999 (Chinn, 1999; Sundar, Varela, \& Naka; Wickremasinghe, 2005)

The absolute PPP relationship can be developed from the Law of One Price which in its absolute version may be written as:

$$
\begin{gathered}
P_{v n, t}=E_{t} P_{u s, t} \\
\text { or } E_{t}=\frac{P_{v n, t}}{P_{u s, t}}
\end{gathered}
$$

where $E_{t}$ is the nominal exchange rate between the VND and the USD, defined as the number of units of VND per unit of the U.S. dollar. $P_{v n, t}$ is the Vietnamese price level and $P_{u s, t}$ the US price level. 
Taking the logarithm of both sides of the (1), the estimable equation for testing PPP is $\ln E_{t}=\propto+\beta \ln \frac{P_{v n, t}}{P_{u s, t}}+u_{t}$

where, $\ln E_{t}$ is the logarithm of the nominal exchange rate at time $t, \ln \frac{P_{v n, t}}{P_{u s, t}}$ is the logarithm of the ratio of the Vietnamese price level to the U.S price level and $u_{t}$ is the error term with zero expectations and represents the deviation from PPP.

In (2), when $\beta=1$, PPP holds exactly, implying that changes in the domestic or foreign price levels are offset by changes in the nominal exchange rate, except for any stochastic shocks. However, if $\beta$ is not equal to one, the exchange rate and price level may still move together in a co-integrated way.

\subsection{Behavioural equilibrium exchange rate (BEER)}

The BEER approach developed by Clark and MacDonald (1999) proposes that a set of fundamental variables have persistent effects on the real exchange rate in the medium to longer terms with the choice of these variables varying by country. This method suggests many candidate variables can explain real exchange rate variation.

In general, the real effective exchange rate is estimated as follows:

$$
R E E R_{t}=\alpha^{\prime} Z_{t}+\beta^{\prime} T_{t}+\varepsilon_{t}
$$

where $\mathrm{Z}$ is the vector of economic fundamentals expected to influence the real exchange rate over the medium and long run, $\mathrm{T}$ is a vector of transitory factors affecting the real exchange rate in the short run, $\varepsilon_{t}$ is a random disturbance term, and REER $_{t}$ is the observed real effective exchange rate.

The economic fundamentals chosen depend on the conditions and structure of the economy including terms of trade, productivity, net foreign assets, public debt, interest rate differentials, public expenditure, openness ratio, real wages, unemployment rates, index of crude oil, and the relative price of non-traded to traded goods (Aliyu, 2009; Bęza-Bojanowska, 2009; Chen, 2007; Clark \& MacDonald, 1999; Égert, Halpern, \& 
MacDonald, 2006; Iossifov \& Loukoianova, 2007; Kemme, Roy, \& Gabrisch, 2003; Maeso-Fernandez, Osbat, \& Schnatz, 2006; Wadhwani, 1999; Wang, Hui, \& Soofi, 2007).

From equation (1) Clark and MacDonald (1999) defined the exchange rate misalignment, Exmis, is the difference between the actual real exchange rate, which is determined by equation (1), and the real exchange rate given by the current values of all economic fundamentals, which is $R E E R^{\prime}{ }_{t}=\alpha^{\prime} Z_{t}$ :

Exmis $=R E E R_{t}-R E E R_{t}^{\prime}=\gamma T_{t}+\varepsilon_{t}$

However, the current values of the economic fundamentals deviate from their long run sustainable level, so total misalignment texmiss is the difference between the actual real rate and the real rate given by the sustainable or long-run values of the economic fundamentals $\left(\overline{Z_{t}}\right)$

texmiss $=R E E R_{t}-\beta^{\prime} \bar{Z}_{t}$

From equations (1), (2), and (3) with several adjustments, total misalignment can be defined as follows:

texmiss $=\gamma T_{t}+\varepsilon_{t}+\beta^{\prime}\left(Z_{t}-\bar{Z}_{t}\right)$

\section{Econometric Approach}

First, we examine the absolute PPP relationship in Vietnam using cointegration analysis. In particular, we test the existence of a long term relationship between the exchange rate and the ratio of price levels in Vietnam using quarterly data collected from the IMF's International Financial Statistics for the period from first quarter of 1995 to second quarter of 2014 that yields 78 observations. ${ }^{1}$ The data includes exchange rate $\left(E_{t}\right)$, Vietnamese price level $\left(P_{v n, t}\right)$ and the U.S price level $\left(P_{u s, t}\right)$.

We employed two tests to examine co-integration of the variables namely the Engle and Granger and Johansen co-integration tests. Both these tests require the variables to be tested for stationarity of the data. We employed four such tests for the sake of

\footnotetext{
${ }^{1}$ The macroeconomic data are available for Vietnam only after the Vietnam government implemented a reform program transferring the economy from central planning model to market model. These reforms came into effect in 1990 and data are available only from 1995.
} 
robustness, Augmented Dickey Fuller (ADF) test (Said and Dickey, 1984), Philips Peron (PP) test (Phillips and Perron, 1988) and Generalized Augmented Dickey Fuller test (GLS-ADF) (Elliott et al., 1996). All these tests are based on Dicky-Fuller approach (Dickey \& Fuller, 1979, 1981) which can be written in the following form that includes a time trend $(t)$ and a constant term $\alpha$.

$$
\Delta y_{t}=\alpha+\gamma y_{t-1}+\lambda t+v_{t}
$$

Here, $y_{t}$ stands for variable to be tested for unit root, $\Delta y_{t}=\left(y_{t}-y_{t-1}\right)$ and $v_{t}$ are the random error with zero mean and constant variance. The null and alternate hypotheses are $H_{0}: \gamma=0$ and $H_{1}: \gamma<0$ where rejection of null hypothesis implies stationarity of the data. The ADF test extends the above approach by including lagged difference of the variable $y_{t}$ where optimal lag length for the test equation is determined by Schwartz information criterion (Schwarz 1978). In contrast, the PP test uses a non-parametric approach for controlling higher order autocorrelation. The GLS-ADF test offer more powerful version of traditional DF type tests by de-trending the data using Generalized Least Square (GLS) method before the unit root test is conducted.

\subsection{The Engle and Granger co-integration test}

The Engle and Granger (1987) test involves estimating the model in equation (2) by the standard OLS regression method and the residuals are tested for stationarity by applying the ADF and the PP unit root tests. If these tests reveal that the residuals are stationary in their levels, then one concludes that the variables in the long-run model are cointegrated, that is they share a common trend even though the variables in the PPP model are individually non-stationary. If the residuals are found to be non-stationary, one would then conclude that the PPP relationship does not hold. This is because, in this case, any short-run deviation from the PPP relationship will be cumulative and permanent and that the variables will not have a common trending relationship.

\subsection{Johansen co-integration test}

The Johansen procedure analyses the cointegration relationship among variables using the following a Vector Auto Regressions (VAR) system 
$\Delta X_{t}=\pi X_{t-1}+\sum_{i=1}^{p} \theta_{i} \Delta X_{t-i}+\mu Z+\epsilon_{t}$

in which $X_{t}$ is an $n \times 1$ random vector, $\epsilon_{t}$ is $\operatorname{NIID}\left(0, \sum_{\epsilon}\right)$, and $\mu$ is a deterministic term. The long term relationships are captured in the coefficient matrix of $\pi$. That is, if the rank of $\pi$, denoted by $r$, is between 0 and $n$, then there are $r$ linear combinations of the variables in the system that are $\mathrm{I}(0)$ or co-integrated.

\section{Results of the PPP Empirical Analysis}

\subsection{Unit root test results}

The results of the Augmented Dickey-Fuller (ADF), Phillips-Perron (PP) and Generalized Augmented Dickey Fuller (GLS-ADF) unit root tests are shown in Table 1. As both series appear to have a constant and a linear trend, they were included in the test equation. Both ADF and GLS-ADF tests show that the exchange rate and price ratio are non-stationary at levels, yet stationary at their first difference at $1 \%$ percent significance level. The PP test indicates that exchange rate variable is stationary at the level as well as first difference. However, the ADF-GLS test, which has greater power than the other two tests indicate that exchange rate has a unit root at its first difference. In terms of the price ratio test statistics of all three tests do not reject the null of a unit root at their levels. Conversely, all three tests points to the same conclusion that the variable is stationary at its first difference and integrated of order I(1) .

\begin{tabular}{cccc}
\hline $\begin{array}{c}\text { Table } 1 \text { Unit root } \\
\text { test for variables }\end{array}$ & $\mathrm{ADF}$ & $\mathrm{PP}$ & GLS-ADF \\
\hline $\ln E_{t}$ & -2.059 & $-3.672^{*}$ & -1.984 \\
$\Delta \ln E_{t}$ & $-9.347^{* *}$ & $-15.886^{* *}$ & $-9.112^{* *}$ \\
$\ln \left(P_{v n, t} / P_{u s, t}\right)$ & -1.436 & -0.940 & -1.106 \\
$\Delta \ln \left(P_{v n, t} / P_{u s, t}\right)$ & $-5.210^{* *}$ & $-5.204^{* *}$ & $-4.476^{* *}$ \\
Test critical values & & & \\
$1 \%$ level & -4.083 & -4.082 & -3.671 \\
$5 \%$ level & -3.470 & -3.469 & -3.107 \\
$10 \%$ level & -3.162 & -3.162 & -2.812 \\
\hline * indicates significance at 10\% level. ** indicates significance at 5\% level.
\end{tabular}

Given the series are integrated of order I(1), we now test for long run cointegration relationship between Vietnamese exchange and price ratio using Engle and Granger test. 


\subsection{The Engle and Granger test results}

The results of the unit root test of the residuals with no constant or a trend term are shown in Table 2 . The residual is stationary at $5 \%$ of significance level in both ADF and PP test. ${ }^{2}$ Consequently, we can conclude that Vietnamese exchange rate $\left(\ln E_{t}\right)$, and the price ratio $\left(\ln \left(P_{v n, t} / P_{u s, t}\right)\right)$ has a long run cointegrating relationship over the study period. This relationship is estimated and presented in Table 3.

Table 2 Unit root test for residual

\begin{tabular}{rcc}
\hline & ADF test & PP test \\
\hline Test statistics & $-1.975^{*}$ & $-2.074^{*}$ \\
Test Critical values & & \\
$1 \%$ level & -2.59575 & -2.59534 \\
$5 \%$ level & -1.94514 & -1.94508 \\
$10 \%$ level & -1.61398 & -1.61402 \\
\hline
\end{tabular}

* indicates significance at $5 \%$ level.

Table 3 Co-integration equation

\begin{tabular}{lcc}
\hline & Variables & Coefficient \\
\hline Constant & & $9.58(0.000)$ \\
$\ln \left(P_{v n, t} / P_{u s, t}\right)$ & & $0.63(0.000)$ \\
$\mathrm{R}^{2}$ & 0.77 \\
Adjusted $\mathrm{R}^{2}$ & & 0.76 \\
\hline
\end{tabular}

Values given in the parenthesis are probability values.

In addition to the method proposed by Engle and Granger (1987), we applied the Johansen (1988) test to ascertain co-integration of the variables as a robustness check.

\subsection{Johansen co-integration test results}

The Johansen cointegration test was carried out for with a bivariate VAR framework with lag length of $5 .^{3}$ The Johansen methodology produces two test statistics, Trace and Maximum Eigenvalue statistics to determine the number of cointegrating vectors. In

\footnotetext{
${ }^{2}$ ADF test used a maximum of 11 lags however, optimum number of lags is one based on Schwarz Information Criterion. The PP test used automated bandwidth estimator employing Bartlett kernel (Andrews, 1991) and Newey-West (Newey and West, 1987) serial correlation correction.

3 The results of three lag length selection tests, Akaike Information Criteria (AIC), Sequential Modified LR test statistics and Final prediction Error (FPE) indicated that the optimal lag length is 5.
} 
Table 4, both these statistics indicate that there is at most one co-integrating relationships between variables at the $10 \%$ significance level.

Table 4 Johansen co-integration test

\begin{tabular}{lcc}
\hline $\begin{array}{c}\text { Hypothesized } \\
\text { No. of CE }(\mathrm{s})[\mathrm{r}]\end{array}$ & $\begin{array}{c}\text { Trace } \\
\text { Statistic }\end{array}$ & $\begin{array}{c}\text { Max-Eigen } \\
\text { Statistic }\end{array}$ \\
\hline None $(\mathrm{r}=0)$ & $19.688(0.059)^{*}$ & $14.812(0.073)^{*}$ \\
At most $1(\mathrm{r} \leq 1)$ & $4.876(0.297)$ & $4.876(0.297)$ \\
\hline *Indicates significant at 10\% level. Figures within parenthesis are probability values \\
from MacKinnon et al (1999) \\
Both co-integration techniques indicate a co-integrating relationship between exchange \\
rate and the relative price ratio between Vietnam and the United States. Based on these \\
results the equilibrium exchange rate and actual exchange rate are plotted in Figure 4 \\
which shows the Vietnamese Dong was overvalued in the period from 1995-1998 and \\
the period from 2004-2010. Meanwhile, it was undervalued in 1999-2003 and in the \\
last two years.
\end{tabular}

Figure 4 The PPP exchange rate and actual exchange rate

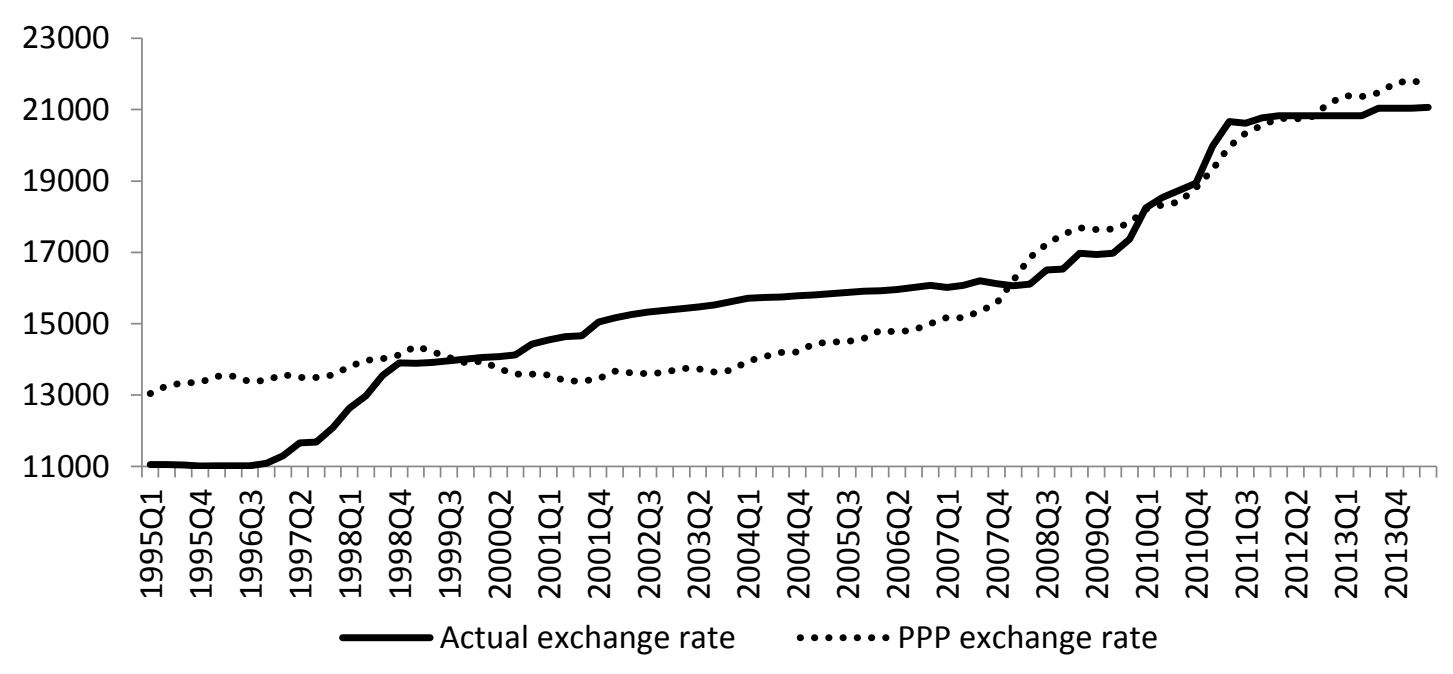




\section{Behavioural Equilibrium Exchange Rate Analysis}

Following Clark and MacDonald (1999), Baffes, Elbadawi, and O'Connell (1997), and Wang et al. (2007), a simple reduced form model of the Behavioural Equilibrium Exchange Rate (BEER) is examined. No previous studies using this approach, which compares the actual real exchange rate with the real exchange rate reflective of international macroeconomic fundamentals, have been conducted for Vietnam. Consistent with other BEER studies for other countries, the fundamental macroeconomic variables chosen for our specification include the terms of trade (tot), net foreign asset $(n f a)$, the degree of openness ( op), and money supply ( $m s$ ).

According to standard international macroeconomic theory, the terms of trade should positively affect the real exchange rate since, other things equal, rising export values should strengthen the exchange rate. The degree of openness also gauges trade exposure, whereas net foreign assets increase as a result of current account surpluses which theory suggests should also be positively related to the exchange rate. On the other hand, a rise in the domestic money supply increases the supply of domestic currency relative to foreign money supplies which should lead to real exchange rate depreciation.

Again, consistent with previous studies, the variables tot, $n f a$, and $o p$ are presumed to have a long-run influence, while $m s$ has both medium and short-run influence. All variables in the estimation are shown in logarithm form. The equilibrium exchange rate was estimated as

$$
\mathrm{BEER}=f(\text { tot }, n f a, \text { op }, m s)
$$

\subsection{Data sources and Definitions}

The monetary authorities in Vietnam do not officially calculate nor publish the real effective exchange rate. In the literature, several studies have compiled the REER, such as Tien (2006) which used annual data to calculate Vietnam's REER for 1999-2004, while Phuc and Duc-Tho (2009) calculated monthly REER from 1995 to 2007. In this study, the REER is defined as the trade weighted index of the inflation-adjusted price of 
domestic currency in terms of foreign currency, so that an increase in REER is a real effective appreciation. ${ }^{4}$

The terms of trade (tot), defined as the ratio of the export price index to the import price index, was sourced from the General Statistical Office of Vietnam. Net foreign asset data $(n f a)$ was sourced from the State Bank of Vietnam and refers to the total stock of net foreign assets accumulated by the State Bank of Vietnam. The degree of openness $(o p)$ is defined as the ratio of total exports and imports to Gross Domestic Product with data sourced from IMF International Financial Statistics. Money supply data $(m s)$ was collected from the State Bank of Vietnam. Monetary approaches to the exchange rate suggest an increase (decrease) in the money supply should cause real exchange rate depreciation (appreciation).

\subsection{Unit root tests}

The Augmented Dickey-Fuller (ADF) and Phillips-Perron (PP) test were used to determine whether the variables of model (5) were stationary in the first difference. We assumed trend and intercept in the test equation. The results are reported in Table 5. The results suggest that there are two variables (lnreer and lntot) integrated of the order one, I(1), implying that the series are stationary in the first difference. The results of the trade openness (lnop) variable is mixed.

We consider ADF-GLS test results as it is the most powerful test that shows the trade openness variable (lnop) is integrated of the order one, I(1). The test results are mixed in the terms of the other trade variable $(\operatorname{lnnfa})$. Only the PP test suggests that this variable is stationary at the first difference. Considering the outcomes of the unit root

\footnotetext{
4 REER is calculated as follows:
}

$$
R E E R_{t}=\prod_{j=1}^{n}\left(e_{j t} \frac{P_{t}}{P_{j t}}\right)^{W_{j t}}
$$

$R E E R_{t}$ is the real effective exchange rate of the home country at time $t ; n$ is the number of trading-partner currencies in the trade basket; $e_{j t}$ is the nominal bilateral exchange rate relative to currency $j$, measured as the number of units of currency $j$ per unit of the domestic currency, and expressed as an index; $w_{j t}$ is the weight assigned to currency $j$ at time $t$, reflecting the contribution of the country of currency $j$ to the home country's foreign trade; and $\bullet P_{t}$ is the domestic price index at time $t$ and $P_{j t}$ is the price index of foreign country $j$ at time $t$. The data sources are as follows. The data for the variables, $e_{j t}$ and $P_{t}$ were collected from VNB. The data for $P j_{t}$ were collected from IMF. The trade weights, $w_{j t}$ are author's calculation using data from Vietnamese General Statistics Office. 
tests, we test for a potential co-integration relationship between REER and these four fundamental macroeconomic variables.

Table 5 Unit root test for variables

\begin{tabular}{|c|c|c|c|}
\hline & ADF & $\mathbf{P P}$ & GLS-ADF \\
\hline lnreer & -3.170 & -3.120 & -3.099 \\
\hline slnreer & $-10.942 * *$ & $-11.009 * *$ & $-10.581 * *$ \\
\hline \multicolumn{4}{|l|}{ Test critical values } \\
\hline $1 \%$ level & -4.08 & -4.08 & -3.67 \\
\hline $5 \%$ level & -3.47 & $-3 . .47$ & -3.11 \\
\hline $10 \%$ level & -3.16 & -3.16 & -2.81 \\
\hline lntot & -1.829 & -1.891 & -1.920 \\
\hline$\Delta l n t o t$ & $-8.385 * *$ & $-8.406 * *$ & $-8.366 * *$ \\
\hline \multicolumn{4}{|l|}{ Test critical values } \\
\hline $1 \%$ level & -4.08 & -4.08 & -3.67 \\
\hline $5 \%$ level & -3.47 & -3.47 & -3.11 \\
\hline $10 \%$ level & -3.16 & -3.16 & -2.81 \\
\hline $\operatorname{lnnfa}$ & -2.712 & -2.566 & -2.754 \\
\hline$\Delta \operatorname{lnnfa}$ & -2.521 & $-13.026 * *$ & -2.564 \\
\hline \multicolumn{4}{|l|}{ Test critical values } \\
\hline $1 \%$ level & -4.09 & -4.08 & -3.69 \\
\hline $5 \%$ level & -3.47 & -3.47 & -3.12 \\
\hline $10 \%$ level & -3.16 & -3.16 & -2.83 \\
\hline $\operatorname{lnms}$ & -03952 & -1.206 & -1.717 \\
\hline$\Delta \operatorname{lnms}$ & $-6.721 * *$ & $-6.599 * *$ & $-6.813 * *$ \\
\hline \multicolumn{4}{|l|}{ Test critical values } \\
\hline $1 \%$ level & -4.08 & -4.08 & -3.68 \\
\hline $5 \%$ level & -3.47 & -3.47 & -3.11 \\
\hline $10 \%$ lelvel & -3.16 & -3.16 & -2.82 \\
\hline lnop & $-8.640 * *$ & $-3.817 *$ & -1.684 \\
\hline$\Delta l n o p$ & $-5.788 * *$ & $-14.421 * *$ & $-5.742 * *$ \\
\hline \multicolumn{4}{|l|}{ Test critical values } \\
\hline $1 \%$ level & -4.09 & -4308 & -3.70 \\
\hline $5 \%$ level & -3.47 & -3.47 & -3.13 \\
\hline $10 \%$ lelvel & -3.16 & -3.16 & -2.83 \\
\hline
\end{tabular}

** indicates significance at $1 \%$ level. * indicates significance at $5 \%$ level.

\subsection{Co-integration test}

Firstly, a VAR in level, including these four I(1) variables, was estimated. Since Johansen methodology is sensitive to the number of lags used in the VAR, the optimal number of lags was selected using three Criterion. They are LR test critical, Final Predictor Error (FDE), and the Akaike information criterion (AIC). The results in Table 6 indicate that the optimal lag length is four. Hence, the lag 4 is chosen in the VAR model. 
Table 6 VAR Lag Order Selection Criteria

\begin{tabular}{ccccc}
\hline Lag & LogL & LR & FPE & AIC \\
\hline 0 & 27.93283 & NA & $3.61 \mathrm{e}-07$ & -0.645995 \\
1 & 483.9366 & 834.9364 & $1.93 \mathrm{e}-12$ & -12.78695 \\
2 & 515.7594 & 53.78510 & $1.61 \mathrm{e}-12$ & -12.97914 \\
3 & 531.0072 & 23.62335 & $2.17 \mathrm{e}-12$ & -12.70443 \\
4 & 573.0000 & $59.14475^{*}$ & $1.42 \mathrm{e}-12^{*}$ & $-13.18310^{*}$ \\
\hline
\end{tabular}

* indicate lag order selected by the criterion. LR: Modified Likelihood Ratio (LR) test statistic. FPE: Final prediction error and AIC: Akaike information criterion.

Table 7 presents the results of Johansen cointegration test. According to the Maximum Eigen-value and Trace statistic there are at most two co-integrating relationships among the variables at $1 \%$ significance level. At 5\% significant level there are three cointegration relationships. The existence of multiple cointegration vectors creates puzzling situation in terms of interpretation of equilibrium condition (Johansen and Juselius, 1992; Dibooglu and Enders, 1995; Wickens, 1996). Hence a single cointegration vector is preferred as such cointegrating relationship could be considered as a linear combination of several stationary vectors. ${ }^{5}$ For this reason, in this situation, 1990 we chose one cointegration vector and follow this in the rest of the analysis.

Table 7 Unrestricted co-integration rank test statistics

\begin{tabular}{ccc}
\hline Hypothesized & Trace & Max-Eigen \\
No. of CE $(\mathrm{s})[\mathrm{r}]$ & Statistic & Statistic \\
\hline None $(\mathrm{r}=0)^{* *}$ & $167.2(0.000)$ & $90.48(0.000)$ \\
At most $1(\mathrm{r} \leq 1)^{* *}$ & $76.72(0.005)$ & $39.21(0.0015)$ \\
At most $2(\mathrm{r} \leq 2)^{*}$ & $37.50(0.027)$ & $21.165(0.07)$ \\
At most $2(\mathrm{r} \leq 3)$ & $16.34(0.159)$ & $11.95(0.1885)$
\end{tabular}

**Indicates significant at $1 \%$ level *Indicates significant at $5 \%$ level. Figures within parenthesis are probability values from MacKinnon et al (1999).

The results from Trace and Max-Eigen statistics yield the normalised cointegrating coefficients in Table 8.

\footnotetext{
${ }^{5}$ See Aliyu, 2007 and Cerra and Saxena 2002 for a similar approach.
} 
Table 8 Normalised cointegrating coefficients

\begin{tabular}{lccccc}
\hline$($ lnREER $)$ & $($ lntot $)$ & $($ lnop $)$ & $($ lnlfa $)$ & $($ lnms $)$ & $\mathrm{C}$ \\
\hline \multirow{2}{*}{1.000000} & -0.4407 & 0.652 & 0.0016 & -0.1058 & 1.239 \\
& $(0.128)$ & $(0.059)$ & $(0.022)$ & $(0.013)$ & $(0.174)$ \\
\hline
\end{tabular}

Figures within parenthesis are probability values

From 8 we obtain the following cointegration equation:

$$
R E E R=1.23-0.44 \ln t o t+0.65 \operatorname{lnop}+0.017 \ln n f a-0.105 \mathrm{~ms}
$$

It can be seen from the estimated equation that all coefficients except for terms of trade conform to underlying economic theory. This equation indicates that the money supply, net foreign asset, and degree of openness have influence on the long-term equilibrium exchange rate. If money supply increases by $1 \%$, the exchange rate will depreciate by $1.05 \%$. Meanwhile, $1 \%$ increase in net foreign asset will appreciate the VND by $0.17 \%$.

The equilibrium VND exchange rate (BEER) is calculated according to equation (6) with actual values of the fundamental variables (tot, $n f a, o p, m s$ ). The H-P filter technique is used to remove the short and random disturbances in BEER to obtain the stable BEER values labelled the equilibrium exchange rate in Figure 5. From this figure it becomes apparent that the VND was overvalued in the periods from 1997Q2 to 2003Q2 and from 2008Q3 to 2013Q4. 
Figure 5 Real effective exchange rate and equilibrium exchange rate

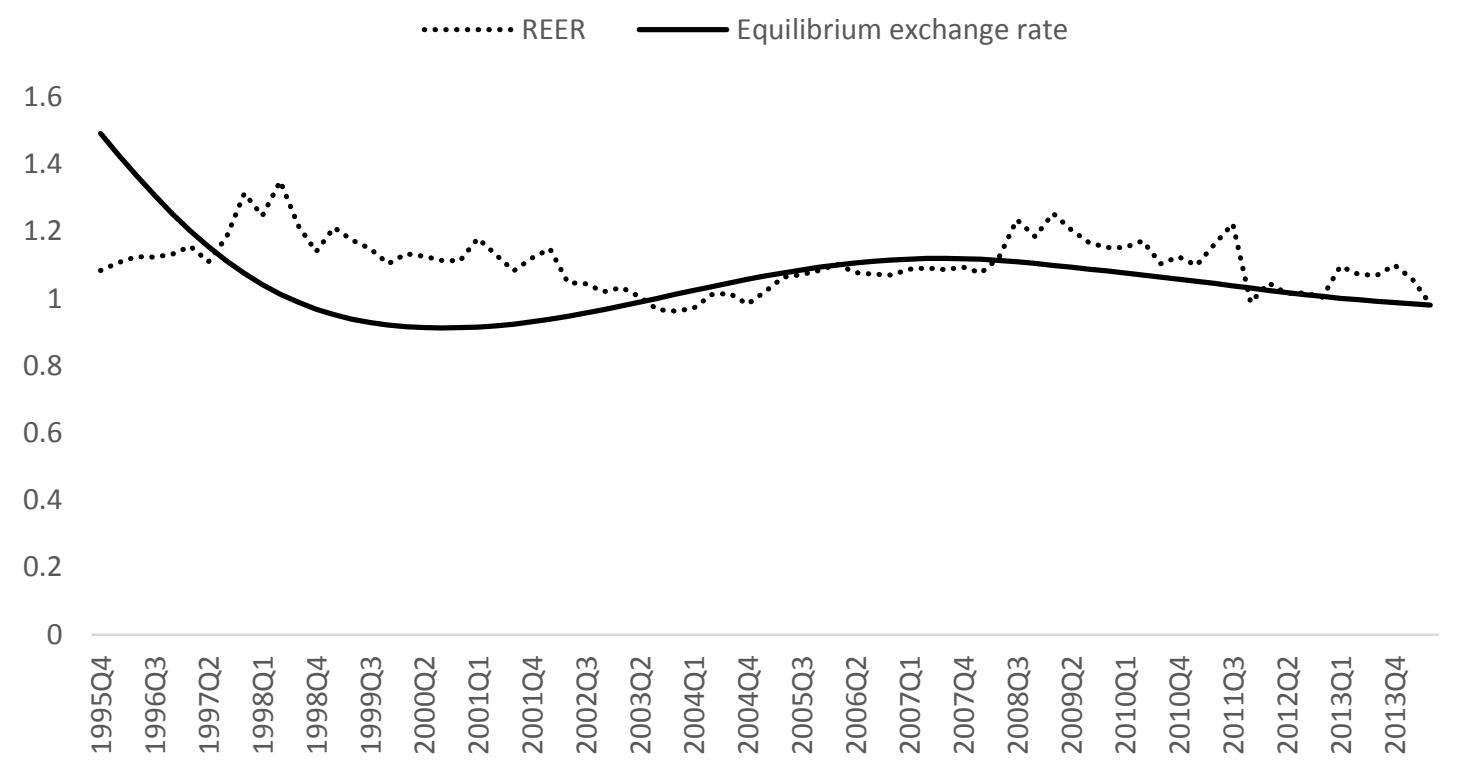

\section{Conclusion}

This paper has addressed the valuation of the Vietnam's exchange rate which the State Bank of Vietnam manages according to economic conditions and which has been pegged for a lengthy time with relatively minor adjustment. The exchange rate is critically important to the conduct and effectiveness of monetary policy and hence to any open economy's overall performance (Makin 2005, 2007). The major finding of this paper is that the VND has been significantly overvalued at times, implying that more significant official adjustments of the nominal exchange rate would have improved Vietnam's competitiveness.

Equilibrium exchange rates were estimated with reference to Purchasing Power Parity (PPP) and the Behavioural Equilibrium Exchange Rate (BEER) approach. Based on quarterly data from 1995 to 2014, our main finding is that both approaches clearly show the Vietnamese Dong was significantly overvalued for extended times over this interval. In other words, the main reason for the extended periods of VND overvaluation over the sample interval was that the official exchange rate was pegged at a level inconsistent with key macroeconomic fundamentals. 
The most important of these fundamentals was Vietnam's relatively high inflation rate compared to inflation rates in its major trading partners, especially the United States. Meanwhile, the money supply and net foreign assets were also shown to have a significant impact on the VND, along with degree of openness. Increases in the terms of trade, net foreign assets, and degree of openness result in real exchange rate appreciation, whereas money supply expansion negatively affects Vietnam's real exchange rate. 


\section{References}

Aliyu, S. U. R. (2009). Real exchange rate misalignment: an application of behavioral equilibrium exchange rate (BEER) to Nigeria. Available at SSRN 1333642.

Anoruo, E., Braha, H., \& Ahmad, Y. (2002). Purchasing power parity: evidence from developing countries. International Advances in Economic Research, 8(2), 85-96.

Arize, A. C. (2011). Purchasing power parity in LDCs: An empirical investigation. Global Finance Journal, 22(1), 56-71. doi: 10.1016/j.gfj.2011.05.005

Baffes, J., Elbadawi, I. A., \& O'connell, S. A. (1997). Single-equation estimation of the equilibrium real exchange rate: World Bank, Development Research Group.

Bahmani-Oskooee, M., \& Goswami, G. G. (2005). Black market exchange rates and purchasing power parity in emerging economies. Emerging Markets Finance and Trade, 41(3), 3752.

Bahmani-Oskooee, M., \& Tanku, A. (2006). Do the black market and the official exchange rates converge in the long run? Journal of Economics and Finance, 30(1), 57-69.

Berger, T., \& Kempa, B. (2009). A new approach to estimating equilibrium exchange rates for small open economies: The case of Canada: Center for Quantitative Economics (CQE), University of Muenster.

Bęza-Bojanowska, J. (2009). Behavioral and Permanent Zloty/Euro Equilibrium. Central European Journal of Economic Modelling and Econometrics, 1(1).

Cerra, V. and S. Saxena. (2002). "What Caused the 1991 Currency Crisis in India?" IMF Staff Papers, 49 (3).

Cassel, G. (1918). Abnormal Deviations in International Exchanges. The Economic Journal, 28(112), 413-415.

Cerrato, M., Kellard, N., \& Sarantis, N. (2008). The Purchasing Power Parity Persistence Puzzle: Evidence From Black Market Real Exchange Rates. The Manchester School, 76(4), 405-423.

Chen, J. (2007). Behavior equilibrium exchange rate and misalignment of Renminbi: A recent empirical study. Paper presented at the DEGIT Conference Papers.

Chinn, M. D. (1999). Measuring misalignment: purchasing power parity and East Asian currencies in the 1990's: International Monetary Fund.

Clark, P. B., \& MacDonald, R. (1999). Exchange rates and economic fundamentals: a methodological comparison of BEERs and FEERs: Springer.

Dibooglu, S., and W. Enders, (1995) "Multiple Cointegrating Vectors and Structural Economic Models: An Application to the French Franc/U.S. Dollar Exchange Rate," Southern Economic Journal, Vol. 61 (April), pp. 1098-1116.

Dickey, D. A., \& Fuller, W. A. (1979). Distribution of the estimators for autoregressive time series with a unit root. Journal of the American statistical association, 74(366a), 427431.

Dickey, D. A., \& Fuller, W. A. (1981). Likelihood ratio statistics for autoregressive time series with a unit root. Econometrica: Journal of the Econometric Society, 1057-1072.

Elliott, G., Rothenberg, T., Stock, J., 1996. Efficient test for an autoregressive unit root.

Econometrica 64, 813-836

Égert, B., Halpern, L., \& MacDonald, R. (2006). Equilibrium Exchange Rates in Transition Economies: Taking Stock of the Issues*. Journal of Economic surveys, 20(2), 257-324.

Iossifov, P. K., \& Loukoianova, E. (2007). Estimation of a behavioral equilibrium exchange rate model for Ghana. IMF Working Papers, 1-21.

Johansen S. and K. Juselius, (1992) "Testing Structural Hypotheses in a Multivariate Cointegration Analysis of the PPP and the UIP for UK," Journal of Econometrics, Vol. 53 (July/September), pp. 211-44.

Kemme, D. M., Roy, S., \& Gabrisch, H. (2003). Exchange rate misalignment: macroeconomic fundamentals as an indicator of exchange rate crisis in transition economies. Empirical Methods for Analyzing the Risks of Financial Crises. Institute for Economic ResearchHalle, Halle (Saale), Germany, 7-32.

Maeso-Fernandez, F., Osbat, C., \& Schnatz, B. (2006). Towards the estimation of equilibrium exchange rates for transition economies: Methodological issues and a panel 
cointegration perspective. Journal of Comparative Economics, 34(3), 499-517. doi: http://dx.doi.org/10.1016/j.jce.2006.05.003

Makin, A.J., (2017) International Money and Finance, Routledge, London.

Makin, A.J., (2007) “To Peg or Not to Peg?” Singapore Economic Review 52(2):39-52.

Makin, A.J., (2005) "A Monetary Model of Exchange Rate and Balance Payments Adjustment" Economic Issues 10 (1), 25-36.

Phillips, P., Perron, P., 1988. Testing for a unit root in time series regression. Biometrika 75, 335-346.

Phuc, N. T., \& Duc-Tho, N. (2009). Exchange rate policy in Vietnam, 1985-2008. ASEAN Economic Bulletin, 26(2), 137-163.

Rogoff, K. (1996). The purchasing power parity puzzle. Journal of Economic literature, 34(2), 647-668.

Said, E., Dickey, D., 1984. Testing for unit roots in autoregressive moving average models of unknown order. Biometrika 71, 599-607.

Sarno, L., \& Taylor, M. P. (2002). The economics of exchange rates: Cambridge University Press.

Stein, J. L. (1993). The natural real exchange rate of the United States dollar and determinants of capital flows: Brown University, Department of Economics.

Sundar, C., Varela, O., \& Naka, A. Black market and official exchange rates, cointegration and purchasing power parity in developing Asian countries. Global Finance Journal, 8(2), 221-238. doi: 10.1016/s1044-0283(97)90017-x

Taylor, A. M., \& Taylor, M. P. (2004). The purchasing power parity debate.

Thanh, N. N., \& Kalirajan, K. (2005). The Importance of Exchange Rate Policy in Promoting Vietnam's Exports. Oxford Development Studies, 33(3-4), 511-529. doi: 10.1080/13600810500199335

Vo, T. T., Dinh, H., Do, X., Hoang, V., \& Phan, C. (2000). Exchange rate arrangement in Vietnam: information content and policy options. Individual Research Project, East Asian Development Network (EADN).

Vu, H. Q., Nguyen, H. T. T., \& Vu, D. P. H. (2013). The exchange rate from 2000 to 2011: The misalignment and its impact on export (Vol. RS-01).

Vuong, Q. H. (2003). Essays on Vietnam's Financial Reforms: Foreign Exchange Statistics and Evidence of Long-Run Equilibrium. Economic Studies Review, 43(6-8).

Wadhwani, S. (1999). Currency puzzles. speech delivered to the London School of Economics, September, 16.

Wang, Y., Hui, X., \& Soofi, A. S. (2007). Estimating renminbi (RMB) equilibrium exchange rate. Journal of Policy Modeling, 29(3), 417-429.

Wickens, M. (1996) "Interpreting Cointegrating Vectors and Common Stochastic Trends," Journal of Econometrics, Vol. 74 (October), pp. 255-71.

Wickremasinghe, G. B. (2005). Purchasing power parity of Papua New Guinea: evidence from the floating exchange rate regime. Applied Financial Economics Letters, 1(6), 335-338.

Williamson, J. (1994). Estimating equilibrium exchange rates: Peterson Institute. 